\title{
SOBRE LA LICITUD DE LA DESTRUCCIÓN DE UNA AERONAVE AGRESORA QUE LLEVA PASAJEROS INOCENTES*
}

\author{
JOAQUÍN GARCÍA-HUIDOBRO** \\ ALEJANDRO MirANDA MONTECINOS***
}

\begin{abstract}
RESUMEN: En este trabajo se analiza críticamente la sentencia del Tribunal Constitucional alemán que declara inconstitucional una ley que permitía derribar aviones secuestrados para cometer atentados terroristas. Se intenta mostrar que, contra lo que señala el Tribunal, la acción de derribar un avión secuestrado no constituye necesariamente un atentado contra la dignidad de los pasajeros inocentes que viajan en él. La tesis defendida en este estudio se apoya en una doctrina desarrollada por los juristas de la Escuela de Salamanca, que exige distinguir entre aquellas acciones en que se procura intencionalmente la muerte de un inocente y aquellas acciones de las que tal muerte se sigue como un efecto colateral.
\end{abstract}

PALABRAS CLAVE: Aviones secuestrados - terrorismo - dignidad humana - principio del doble efecto

\section{ON THE PERMISSIBILITY OF SHOOTING DOWN AN AGGRESSOR PLANE CARRYING INNOCENT PASSENGERS}

ABSTRACT: This paper critically analyzes the judgment of the German Constitutional Court that declared unconstitutional a law allowing shooting down planes that have been hijacked to commit terrorist attacks. It is attempted to show that, against the Court's opinion,

\footnotetext{
* Este trabajo se realizó con ayuda de Fondecyt (nn. 1110452 y 11121483). Los autores agradecen los comentarios de los profesores Juan Cruz, Santiago Orrego, Paul-Ludwig Weinacht, Sergio Raúl Castaño y Santiago Legarre. Una primera versión de este trabajo, mucho más breve, se publicó en: García-Huidobro, Joaquín y Miranda, Alejandro (2010). “Cabe destruir una nave agresora en la que viajan pasajeros inocentes? Los autores del Siglo de Oro ante una cuestión actual”. En Cruz, Juan (editor): Delito y pena en el Siglo de Oro, Pamplona: Eunsa, pp. 125-137.

Fecha de recepción: 18 de diciembre de 2012.

Fecha de aceptación: 17 de agosto de 2013.

** Abogado y Doctor en Filosofía. Profesor del Instituto de Filosofía de la Universidad de los Andes, Santiago de Chile. Correo electrónico: jgh@uandes.cl

*** Abogado y Doctor en Derecho. Profesor de la Facultad de Derecho de la Universidad de los Andes, Santiago de Chile. Correo electrónico: amiranda@uandes.cl
} 
the action of shooting down a hijacked plane is not necessarily a violation of the dignity of innocent passengers traveling in it. The thesis defended in this paper is based on a doctrine developed by the jurists of the School of Salamanca, which requires distinguishing between those actions that intentionally seek the death of an innocent and those actions that bring about such a death as a side effect.

KEY WORDS: Hijacked planes - terrorism - human dignity - principle of the double effect

Desde hace siglos la Tradición Central ${ }^{1}$ de la ética y la filosofía jurídica occidentales se ha planteado la cuestión de los límites que se imponen a quien participa de una guerra justa. Esta reflexión se aplica analógicamente al combate del terrorismo, que es una peculiar forma de enfrentamiento bélico, en la que el agresor habitualmente se caracteriza precisamente por no aceptar límite alguno. Algunos, como Leo Strauss, han pretendido ampliar al máximo estos límites. Señala este autor que la licitud de lo que se puede hacer en una guerra depende por completo de lo que hace el enemigo, de manera que, si el enemigo es una potencia totalitaria o una agrupación sin escrúpulos, el margen de maniobra de los defensores del orden es amplísimo ${ }^{2}$. Así, "algunas veces (en situaciones extremas o urgentes) es justo apartarse incluso de los principios más generales del derecho natural" 3 . Con todo, esta es una posición minoritaria dentro de esa tradición, de modo que, de Aristóteles a Kant, pasando por Tomás de Aquino, se afirma que hay ciertas acciones que nunca es lícito llevar a cabo ${ }^{4}$.

La llegada del siglo xxi trajo consigo la irrupción de formas inéditas de terrorismo y, como consecuencia, la necesidad de hacerles frente. Entre esas formas novedosas está la utilización de aeronaves civiles que son secuestradas y empleadas como proyectiles por terroristas dispuestos a autoinmolarse. Como estas naves van cargadas de pasajeros civiles, se presenta el problema de si es lícito usar la fuerza contra ellas como medio de defensa, aunque eso signifique la muerte segura de civiles inocentes. El problema es importante, entre otras razones, porque da cuenta de una convicción constante en la Tradición Central de Occidente en el campo

1 Sobre el uso de esta expresión, tomada de I. Berlin, véase George, Robert P. (1993). Making Men Moral. Civil Liberties and Public Morality, Oxford: Clarendon Press, p. 19, nota 2. Strauss, Leo (1953). Natural Right and History. Chicago: University of Chicago Press, pp. 157 y ss.

3 Strauss, Leo (1996). Persecución y arte de escribir y otros ensayos de filosofía politica, Valencia: Edicions Alfons el Magnànim, pp. 140-143.

4 Aristóteles, EN II 6, 1107a9-17. 
de la ética, a saber, que las actividades bélicas deben someterse a los dictados de la razón. Dicho con otras palabras, lo anterior supone dos cosas relevantes: primero, que la guerra puede ser justa y, segundo, que en la guerra, por muy justa que pueda ser, no vale todo. Con esto, la tradición busca distanciarse tanto de los inmoralismos pragmáticos, que piensan que en la guerra todo está permitido, como del pacifismo, que sostiene que toda guerra es, necesariamente, injusta.

En las páginas que siguen comentaremos un caso relativamente reciente, donde entran en consideración problemas de gran interés acerca de la forma de respetar a civiles inocentes. Se trata de un fallo del Tribunal Constitucional alemán que se refiere a una ley sobre la materia (1, 4-5). Lo contrastaremos con las soluciones que, para un caso semejante, proponían los teólogos y juristas españoles de los siglos XVI y XVII (2), con el modo de ver el problema que es propio del consecuencialismo ético (3) y con los criterios kantianos que emplea el propio tribunal para declarar la inconstitucionalidad de la disposición que permitía derribar aviones secuestrados (6).

\section{1) UNA LEY ALEMANA}

Los sucesos del 11 de septiembre de 2001 en los Estados Unidos provocaron diversas reacciones en el resto del mundo y, en particular, la adopción de medidas más estrictas para combatir el terrorismo. En este contexto, el Parlamento alemán dictó el 15 de enero de 2005 una Ley de Seguridad Aérea en la que, junto con reforzarse las medidas de seguridad en aeropuertos y aviones, se incluía una disposición que permitía el uso de la fuerza para derribar aviones secuestrados que fueran a ser utilizados para atacar objetivos estratégicos, con la consiguiente pérdida de vidas, como sucedió en el famoso atentado contra las Torres Gemelas de Nueva York. Esta disposición, contenida en el artículo 14 inciso 3 de la citada ley ${ }^{5}$, fue objeto de un requerimiento de inconstitucionalidad y de una amplia discusión en la opinión pública ${ }^{6}$. Entre los argumentos que se dieron a favor

5 «La directa intervención mediante la fuerza de las armas solo estará permitida cuando de acuerdo con las circunstancias se debe suponer que la aeronave va a ser utilizada contra la vida de seres humanos y esa fuerza es el único medio para repeler ese peligro inminente».

6 Un panorama de esta discusión en Rodríguez de Santiago, José M. (2006). "Una cuestión de principios. La Sentencia del Tribunal Constitucional Federal alemán de 15 de febrero de 2006, sobre la Ley de Seguridad Aérea, que autorizaba a derribar el avión secuestrado para cometer un atentado terrorista”. Revista Española de Derecho Constitucional, Vol. 77, pp. 257-272, de donde se toman las traducciones castellanas de la sentencia comentada. Véase también Ladiges, Manuel (2007). Die Bekämpfung nicht-staatlicher Angreifer im Luftraum unter besonderer Berücksichtigung des $\$ 14$ Abs. LuftSiG und der strafrechtlichen Beurteilung der Tötung von Unbeteiligten, Seiten: Duncker \& Humblot Verlag, p. 557; Ladiges, 
de esta ley está la necesidad de proteger las vidas de los potenciales afectados por estos atentados, que son inocentes y, normalmente, más numerosos que los pasajeros del avión. Por otra parte, se decía, estos últimos están condenados a sufrir una muerte inevitable, que se producirá en cuanto el avión se estrelle contra su objetivo final ${ }^{7}$. En definitiva, los pasajeros y la tripulación han pasado a formar parte del arma en que ha sido transformado el avión (párr. 134). Por último, se afirmaba que cabe pedir a esos pasajeros un sacrificio en aras del bien común (párr. 135). Como se ve, buena parte de la argumentación esgrimida presenta un carácter utilitarista, que lleva a considerar como preferible salvar una mayor cantidad de vidas antes que una más pequeña, especialmente cuando el valor de estas, concretamente de los pasajeros del avión, se halla disminuido por la posibilidad cierta de muerte en cuanto el ataque se lleve a cabo. También se dice que, al abordar el avión, la tripulación y los pasajeros están consintiendo en la posibilidad de que se tomen medidas extremas en el caso de que tenga lugar un incidente aéreo como el contemplado por la ley (párr. 131).

Los argumentos contrarios a la ley fueron de índole muy variada. Algunos la impugnaron por razones de técnica legislativa, otros sostuvieron que no se cumplían ciertos supuestos de hecho mínimos para que pueda tomarse una decisión tan radical, atendida la dificultad de comunicar información fidedigna de lo que está sucediendo en el avión (párr. 126-128). Finalmente, el grueso de las objeciones presentaba una clara influencia kantiana y se fundaban en el carácter inviolable de los derechos afectados. Todos estos argumentos contrarios a la ley fueron recogidos por el Tribunal Constitucional en su sentencia de 15 de febrero de 2006.

Antes de entrar al análisis de las razones del tribunal alemán, nos interesa mostrar cómo los autores del Siglo de Oro español ya habían tratado, en su discusión acerca de las condiciones de la guerra justa, varias de las cuestiones que se presentan en el debate actual acerca de la posibilidad de derribar una aeronave secuestrada que lleva pasajeros inocentes.

\section{2) La SOlución de la Escuela de Salamanca}

El problema que estamos tratando dista de ser original y ya había sido planteado hace más de cuatro siglos en el seno de las Escuelas de Salamanca y Coimbra. Concretamente, Luis de Molina se había preguntado por la lici-

Manuel (2008). "Die notstandbedingte Tötung von Unbeteiligten im Fall des $₫ 14$ Abs. 3 LuftSiG -ein Plädoyer für die Rechtfertigungslösung". Zeitschrift für Internationale Strafrechtsdogmatik, Vol. 3, pp. 129-140.

7 BVerfG, 1 BvR 357/05 vom 15.2.2006, Absatz-Nr. 132. Disponible en http://www.bverfg. de/entscheidungen/rs20060215 1bvr035705.html (al 2.9.13). En lo sucesivo se citarán los párrafos respectivos en el cuerpo del artículo. 
tud de destruir una nave agresora enemiga (turca, en su ejemplo) cuando ella llevaba como remeros rehenes cristianos. Su respuesta era la siguiente:

"Per accidens, con intención de matar a los nocentes, es lícito matar inocentes, incluso a sabiendas. Así, cuando se ataca justamente una fortaleza o una ciudad en la que consta que algunos inocentes están mezclados con los nocentes, es lícito bombardearla o incendiarla o hacer cualquier otra cosa para conquistarla, aunque se sepa que per accidens, esto es, fuera de la intención (praeter intentionem) de quienes lo hacen, morirán algunos inocentes. Cuando se sabe que en los trirremes turcos hay remeros cristianos, es lícito dispararles con las bombardas para destruirlos y pelear contra ellos, aunque se sepa que se matará a los remeros al mismo tiempo que a los turcos" ${ }^{8}$.

Hemos citado este pasaje de Molina en virtud de la particular semejanza que su ejemplo de las naves turcas guarda con el caso de los aviones secuestrados. Pero, ciertamente, no fue Molina el único de su tiempo en sostener esta opinión. Más bien, como escribe Pedro de Ledesma, estamos aquí en presencia de una "común sentencia de todos los teólogos y juristas" 9 . En efecto, ya Vitoria había defendido la relevancia moral de la distinción entre matar per se o ex intentione y matar per accidens o praeter intentionem. En su relección De homicidio recurre a ella para diferenciar el suicidio de algunas acciones lícitas de las que se sigue, incluso con certeza, la propia muerte ${ }^{10}$. Pero es en su relección De jure belli donde presenta el caso más atingente al problema que ahora nos ocupa. Enseña aquí el jurista hispano que nunca es lícito matar a los inocentes per se o ex intentione; pero luego añade que "per accidens, algunas veces es lícito matar inocentes incluso a sabiendas, como cuando se ataca justamente una fortaleza o una ciudad, en la cual consta que hay muchos inocentes, y no pueden emplearse máquinas de guerra, ni armas arrojadizas, ni ponerse fuego a los edificios, sin que padezcan tanto los inocentes como los nocentes" 11 . Vitoria propone, de este modo, el ejemplo más común de la

8 Molina, Luis de (1593). De iustitia et iure, tr. 2, disp. 119. Se cita según la edición de Ioannis Masselini, Conchae, 1593. Hay que tener presente que, dentro de los nocentes, hay que incluir no solo al que tiene culpa, sino también al que se encuentra en una posición injusta y causa dańo, aunque subjetivamente no haya pretendido hacerlo, como sucede en el caso de un demente. Los clásicos no caen en el error contemporáneo de criminalizar al adversario. Así, es perfectamente posible suponer la buena fe de los soldados enemigos dentro de una guerra justa.

9 Ledesma, Pedro de (1605), Segunda parte de la Summa, tr. 3, c. 13. Se cita según la edición de Antonia Ramírez, Salamanca, 1605.

$10 \quad$ Vitoria, Francisco de (1529), De homicidio, nn. 25, 27, 31 y 37.

11 Vitoria, Francisco de (1539). De indis posterior, sive De jure belli hispanorum in barbaros, n. 37. Se cita según la edición crítica bilingüe de Teófilo Urdánoz (1960) en Obras de Francisco 
aplicación de la doctrina moral que más tarde cristalizará con el nombre de principio del doble efecto o principio del voluntario indirecto. Y, a continuación, el fundador de la Escuela de Salamanca se detiene a precisar otros requisitos que él juzga necesarios para la licitud de la acción, además de aquel que exige que la muerte se siga de manera no intencionada (praeter intentionem). En primer lugar, Vitoria repara en la necesidad de una adecuada proporción entre el efecto bueno y el efecto malo. Esto quiere decir que el bien que se pretende alcanzar con la acción debe ser suficientemente importante como para que se justifique realizarla a pesar de que de ella se siga el efecto malo. Por eso escribe el autor que "si para conseguir la victoria principal en una guerra, representa poco el atacar una fortaleza o una ciudad en que hay guarnición enemiga, y hay alli muchos inocentes, no parece lícito que para combatir a unos pocos nocentes se pueda matar a muchos inocentes"12.

En segundo lugar, Vitoria deja en claro que la acción de la que se sigue el efecto malo debe ser necesaria para alcanzar el efecto bueno, en el sentido de que no debe haber otra manera menos perjudicial de alcanzarlo. Por ello dice que "nunca parece lícito matar inocentes, incluso per accidens et praeter intentionem, sino cuando la guerra justa no puede desenvolverse de otro modo"13.

En todos estos casos podemos advertir que los autores distinguen perfectamente el objeto físico de la acción de su objeto moral, de modo que lo decisivo aquí no es el resultado que materialmente se produzca, sino qué tipo de acción se está llevando a cabo. Y para especificar la acción es fundamental determinar qué es lo que, en cada caso, quiere la voluntad de modo directo. No es, entonces, primariamente, un problema de la intención, entendida como aquello que remotamente se quiere conseguir con el acto que se está realizando (finis operantis), sino de lo que objetivamente se elige, como fin próximo o medio. En ninguno de los casos que hemos citado se está eligiendo, ni como fin ni como medio, la muerte de los inocentes, sino simplemente el rechazo de la agresión. Esto vale también, como veremos, para el problema del avión secuestrado por terroristas y transformado en un misil. En uno y otros, el rechazo de la agresión se produce no porque los inocentes mueran sino a pesar de que ellos mueran. Lo que directamente se está haciendo no es, per se, matarlos, sino un acto distinto, aunque de hecho ellos mueran.

La doctrina del doble efecto está necesariamente ligada a la admisión de la idea, ya señalada por Aristóteles, de que hay actos que son malos en

de Vitoria. Relecciones teológicas, Madrid: Biblioteca de Autores Cristianos, de cuya traducción castellana nos apartamos ligeramente.

12 Vitoria (1539) n. 37.

13 Vitoria (1539) n. 37. 
sí mismos, no por sus excesos ni defectos ${ }^{14}$. Es decir, solo se entiende si se acepta el papel central que tiene el objeto (finis operis) dentro de las fuentes que permiten determinar la moralidad de un acto. La influencia de las concepciones utilitaristas y sus derivados en los dos últimos siglos ha llevado a criticar la doctrina de los actos intrínsecamente malos y, de paso, es uno de los factores que ha relegado a un segundo plano la doctrina del doble efecto. Estas concepciones han sido objeto de una crítica expresa y han terminado por ser desplazadas en favor de otros modos de argumentar. Sin embargo, esta preterición no queda sin consecuencias, como veremos más adelante, a propósito de la sentencia alemana sobre la Ley de Seguridad Aérea.

\section{3) REQUISITOS PARA LA LICITUD DE LA ACCIÓN DE DOBLE EFECTO}

Ya hemos visto que Vitoria, en su análisis de la moralidad de la acción bélica de la que se siguen bajas civiles, exigía como requisito que no debía existir otra manera menos perjudicial de alcanzar el efecto bueno. Si la hay, evidentemente, se debe optar por ella. Nosotros suponemos, pues, por hipótesis, que en nuestro caso la condición exigida por Vitoria sí se cumple, es decir, que no hay otra manera de detener el avión-misil más que derribándolo. Pero Vitoria requería, además, lo que podría caracterizarse como una adecuada proporción entre el efecto bueno y el efecto malo. ¿Se cumple este requisito en el caso que nos ocupa? Los moralistas siempre han estado conscientes de que esta cuestión solo puede apreciarse prudencialmente atendiendo a las circunstancias del caso concreto. Sin embargo, algunos de ellos -entre los que se puede contar al mismo Vitoria- propusieron algunos criterios generales que permiten orientar el juicio. La labor de sistematización de estos criterios fue llevada a cabo por el moralista español Domingo de Santa Teresa, autor del tratado De vitiis et peccatis del Cursus theologicus salmanticense. Así, según Domingo, la causa o razón excusante (i. e., el efecto bueno) debe ser tanto mayor cuanto:

i) más grave es el efecto malo;

ii) más próximo es el efecto malo;

iii) más determinada está la causa al efecto malo;

iv) más seguro es que se seguirá el efecto malo; y

v) menos vías hay para impedir el efecto malo después de que se ha puesto la causa ${ }^{15}$.

Collegil salmanticensis fF. discalceatorum b. Mariae de Monte Carmeli primitivae observantiae, Cursus theologicus, tr. 13, De vitiis et peccatis (1658), disp. 10, dub. 6, par. 5, n. 247. Hemos consultado la edición de Joannis Antonii Huguetan et soc., Lugduni, 1679. 
No desarrollaremos aquí todos los puntos que menciona el salmanticense, sino solo el (i) y el (iv), a los que, en definitiva, pueden reducirse todos los demás. Por el criterio (i), por ejemplo, se debe considerar que un efecto dañino para la sociedad en general tiene más importancia que uno que solo daña a un individuo o a un conjunto de individuos. En otras palabras, cabe aquí atender a la preeminencia del bien común por sobre el bien particular. Tomás de Aquino, por ejemplo, sostiene que es un acto virtuoso el del soldado que, en la guerra, expone a peligro su propia vida por el bien común espiritual o temporal de la república. Y la razón que ofrece para ello es que "el bien común de muchos es más divino que el bien de uno solo" 16 . El criterio (iv) nos dice, por una parte, que si la probabilidad de que se produzca el efecto malo es baja, mayores razones tendremos para actuar, $y$, por otra, que mientras más seguro sea que se evitará el efecto malo absteniéndose de actuar, más graves habrán de ser nuestras razones para poner la causa. De acuerdo con esto último, por ejemplo, si ya se ha determinado que la voluntariedad de causar el efecto malo es solo indirecta, es decir, que el efecto malo no es querido ni como fin ni como medio, el hecho de que ese efecto se vaya a producir tanto en caso de que actuemos como de que no actuemos -debido a otra causa- es un factor relevante para realizar la acción ${ }^{17}$. ¿Cuenta, entonces, para justificar la licitud de la acción, el argumento de que los pasajeros inocentes van a morir en cualquier caso? Sí, pero no como si él fuera suficiente para justificarla. Más bien, el hecho de que los pasajeros vayan a morir de todos modos cuenta para determinar si hay o no razón proporcionada para actuar. Pero esto, repetimos una vez más, supone que ya se ha despejado el problema de la voluntariedad, esto es, que se ha determinado que la muerte de los pasajeros no es querida ni como fin ni como medio, sino que es solo el efecto colateral del acto de detener el ataque terrorista, que, de suyo, no es otra cosa que un acto de legítima defensa de terceros.

La doctrina expuesta por Vitoria en su tratamiento del ius in bello ha dado origen a la distinción moderna entre bombardeo estratégico (o táctico) y bombardeo aterrorizador. En la primera acción, con el fin de mermar la capacidad bélica del enemigo y asegurar la victoria en la guerra, el

Otros moralistas posteriores agregan el siguiente número a la lista de Domingo: (vi) mayor es la obligación de impedir el efecto malo en razón del estado u oficio del agente.

16 Aquino, Tomás de, Summa Theologiae, II-II, q. 31, a. 3, ad 2.

17 Entre los autores del Siglo de Oro, Juan Azor, por ejemplo, enseña que es lícito a una mujer embarazada huir corriendo para salvarse del fuego, de un torrente de agua, de la cólera de un enemigo o de un ataque bélico, aun cuando esto pueda implicar la muerte del feto. En efecto, en ninguno de estos casos la madre busca la muerte de feto como medio para salvarse. Ahora bien, siendo así las cosas, puede estimarse, además, que la madre goza de una razón proporcionada para actuar, pues, como agrega Azor, «si no corre y huye se exponen al peligro de muerte tanto la madre como el feto", Azor, Juan, Institutionum moralium, pars 3 (póstuma, 1611), 1. 2, c. 3. Se cita según la edición de Io. Baptistam Bozzolam, Brixiae, 1621. 
ejército bombardea un blanco militar definido -como una fortaleza, una nave o una fábrica de armamentos del enemigo-, previendo, sin embargo, que morirán algunos civiles que se encuentran físicamente cerca o incluso al interior del objetivo militar. En la segunda acción, en cambio, el ejército bombardea deliberadamente poblaciones civiles del país enemigo, con el preciso fin de que la muerte de sus ciudadanos inocentes (mujeres y niños) cause terror y desmoralice al adversario. En el bombardeo estratégico, por consiguiente, la muerte de los inocentes no es querida ni como fin ni como medio, solo se tolera como un efecto colateral ligado a lo que directamente se quiere. Claramente, no es la presencia de los inocentes lo que motiva la acción de bombardear el blanco u objetivo militar, y sus muertes no contribuyen en modo alguno a la destrucción de dicho objetivo: la nave turca enemiga no se destruye porque mueren los rehenes cristianos utilizados como galeotes. Por el contrario, en el bombardeo aterrorizador la muerte de los civiles inocentes es elegida como medio para causar terror y desmoralizar al enemigo ${ }^{18}$.

La relevancia moral de esta distinción ha gozado de una aceptación bastante general, y no solo por parte de autores afines a la tradición escolástica en la que ella fue principalmente desarrollada ${ }^{19}$. El moderno derecho de guerra también la ha recogido, y ha declarado que el bombardeo aterrorizador jamás puede ser aceptado, mientras que el bombardeo estratégico sí puede justificarse cuando se cumplen aquellas condiciones que ya en su época exigía Vitoria. Así, el Protocolo I Adicional a los Convenios de Ginebra, por ejemplo, contiene sendas disposiciones que dan cuenta de la importancia de la distinción. Su artículo 51 inciso 2 prohíbe expresamente los actos de ataque que tengan por objeto la población civil. Por su parte, el artículo 57 inciso 2 permite realizar acciones de ataque contra objetivos militares aun cuando se prevea que ellas puedan causar, como efecto incidental, la muerte de civiles. Pero para esto último exige, primero, que se adopten las medidas posibles para evitar o minimizar dichas muertes y, segundo, que estos daños colaterales no sean excesivos en relación con la ventaja militar concreta y directa que se espera obtener del ataque ${ }^{20}$.

Con todo, algunos autores, principalmente aquellos que propugnan una ética consecuencialista, niegan la relevancia moral de esta distinción. Para ellos, los agentes morales son igualmente responsables por todas las consecuencias previsibles de sus cursos de acción, por lo que la mo-

18 Quinn, Warren (1989). "Actions, Intentions, and Consequences: The Doctrine of Double Effect". Philosophy and Public Affairs, Vol. 18 pp. 334-351, p. 336.

19 Además del propio Quinn, citado en la nota precedente, véase NAGEL, Thomas (1972). "War and Massacre". Philosophy and Public Affairs, Vol. 1, pp. 123-144.

20 Véase Protocolo Adicional a los Convenios de Ginebra del 12 de agosto de 1949 relativo a la Protección de las Victimas de los Conflictos Armados Internacionales (Protocolo I). Este protocolo fue aprobado el 8 de junio de 1977 por la Conferencia Diplomática sobre la Reafirmación y el Desarrollo Internacional Humanitario Aplicable en los Conflictos Armados. 
ralidad, en definitiva, se determina por un cálculo o balance de dichas consecuencias ${ }^{21}$. No podemos abordar aquí una crítica de esta tesis ética. Ello, por lo demás, ya ha sido hecho de manera contundente por otros autores ${ }^{22}$. Solo queremos mostrar cómo un autor familiar al consecuencialismo llega a una conclusión, en principio, semejante a la del Tribunal alemán. Jonathan Bennett nos servirá como ejemplo. Bennett afirma que elegir la muerte de los civiles como medio implica usar a las personas como medios para un fin. Según la distinción clásica, en el bombardeo aterrorizador se haría esto, mientras que en el bombardeo estratégico no, por lo que no sería inmoral. En cambio, sí lo sería el bombardeo aterrorizador, pues los agentes morales están sometidos a la exigencia moral de no tratar nunca a las personas como un mero medio. Sin embargo, Bennett piensa que, aunque el principio que manda no tratar a las personas solo como medio es correcto, él se viola no solo donde el dańo a los intereses de la persona es nuestro medio, sino también donde dicho daño es un subproducto de nuestro medio, por lo que no habría diferencia moral entre los dos casos bajo análisis ${ }^{23}$. Según Bennett, para que el principio sea relevante en nuestro caso "no solo debe absolver al bombardero táctico de usar a los civiles como un medio, sino que debe implicar que los está tratando como fines" 24 . Y el autor termina exclamando: “¡Díganle eso a los civiles!" 25. Pero Bennett va más allá aún, y afirma que lo que el bombardero táctico hace a los civiles es, de algún modo, peor que tratarlos como medio: "Él los trata como nada; ellos no desempeñan ningún papel en su plan; él no los trata ni siquiera como medios" 26 .

Las conclusiones de Bennett no nos parecen verdaderas. En primer lugar, ya hemos visto por qué en el bombardeo estratégico no se trata a los civiles como medios: nada de lo que caracteriza a lo que es medio respecto de un fin está presente en la relación que guarda la muerte de los inocentes respecto de la destrucción del blanco militar. Pero, en segundo lugar, tampoco es verdad que en el bombardeo estratégico se trate a los civiles como nada. Precisamente, los requisitos que Vitoria exigía como adicionales al

21 El término "consecuencialismo" para designar estas doctrinas procede de Elizabeth Anscombe: Anscombe, Gertrude Elizabeth Margaret (1958). "Modern Moral Philosophy". Philosophy, Vol. 33, pp. 1-19.

22 Finnis, John (1980). Natural Law and Natural Rights. Oxford: Clarendon Press, pp. 111-125 y Spaemann, Robert (2003). "Sobre la imposibilidad de una ética teleológica en sentido universal”. En Spaemann, Robert, Limites: Acerca de la dimensión ética del actuar. Traducción de Fernández, Javier y Mardomingo, José, Barcelona: Eunsa, pp. 185-204.

23 Bennett, Jonathan (2001). "Foreseen Side Effects versus Intended Consequences". En Woodward, P. A. (editor): The Doctrine of Double Effect. Philosophers Debate a Controversial Moral Principle. Indiana: University of Notre Dame Press, pp. 85-118, p.109. De ahí que él acepte ambas formas de bombardeo.

24 Bennett (2001) 109.

25 Bennett (2001) 109.

26 Bennett (2001) 109. 
hecho de que la muerte fuera un efecto praeter intentionem constituyen una demostración de la fundamental consideración que se tiene hacia los civiles inocentes. En otras palabras, la exigencia de proporcionalidad contenida entre los requisitos clásicos del principio del doble efecto nos viene a decir que no basta, para la licitud de la acción, que el daño a los inocentes no sea empleado como medio para un fin: se debe tener ante ellos una adicional consideración de justicia, que nos obligará a desistir de la acción si el bien que se busca no es suficientemente importante como para tolerar el efecto colateral, o si podemos alcanzar el efecto bueno buscado de una manera que no conlleve el daño para los inocentes. Finalmente, a la exclamación irónica de Bennett - “iDíganle eso a los civiles!”- se puede replicar con un testimonio real, que muestra que incluso desde la perspectiva de la víctima existe una diferencia entre que nuestra muerte se produzca como efecto colateral de una acción lícita y proporcionada y que se produzca porque fue buscada intencionalmente. En efecto, cuentan los sobrevivientes de los campos de concentración alemanes que, aunque consideraban que una muerte en manos de sus captores resultaba absurda, no estimaban lo mismo en los momentos en que los bombardeos aliados hacían prever que una bomba podía caer sobre ellos y darles muerte ${ }^{27}$.

Cuando Tomás de Aquino escribió las líneas en las que tiene su origen la reflexión sobre el principio del doble efecto, se limitó a decir que la relevancia moral de la distinción entre efectos intentados y efectos praeter intentionem se debe a que "los actos morales reciben la especie de lo que se intenta, y no de aquello que es praeter intentionem, puesto que esto es per accidens" 28 . Los moralistas de los siglos XVI y XVII, que elevaron el razonamiento del doble efecto a la categoría de un principio moral de aplicación general, repitieron usualmente la sentencia de Santo Tomás, pero no desarrollaron una justificación más precisa de por qué ciertos efectos malos que jamás es lícito intentar (como la muerte del inocente) pueden, sin embargo, ser causados como efecto colateral previsto (y con certeza) de una acción en la que se intenta un bien proporcionalmente importante. Joseph Boyle, uno de los principales tratadistas contemporáneos del principio del doble efecto, sostiene que la ausencia de una argumentación más profunda por parte de los antiguos moralistas puede deberse a que vieron la significación de la distinción como obvia, en virtud de la analogía que ella guarda con lo que sucede en la acción creadora divina ${ }^{29}$. Dios, en efecto, solo intenta el bien, pero permite, como efecto praeter intentionem o colateral, los males anejos a las naturalezas que crea.

\footnotetext{
27 Recogemos el testimonio de Kaczor, Christopher (2006). "The Violinist and Double-Effect Reasoning". The National Catholic Bioethics Quarterly, Vol. 6, pp. 661-669, p. 665.

28 Aquino, Tomás de, Summa Theologiae, II-II, q. 64, a. 7, c.

29 Boyle, Joseph (2004). "Medical Ethics and Double Effect: The Case of Terminal Sedation". Theoretical Medicine and Bioethics, Vol. 25, pp. 51-60, p. 56.
} 
Solo en el siglo xx los filósofos se ven forzados a justificar con más precisión la relevancia moral que la tradición ha conferido a la distinción entre lo intentado y lo praeter intentionem. Sin embargo, Santo Tomás y sus comentadores escolásticos, en particular los teólogos y juristas espańoles de los s. XVI y XVII, sientan las premisas para elaborar un argumento que orientará la reflexión crítica del fallo que expondremos más adelante ${ }^{30}$.

\section{4) LA DECLARACIÓN DE INCONSTITUCIONALIDAD}

El tema que nos ocupa fue objeto, como se dijo, de una sentencia del Tribunal Constitucional alemán, dictada el 15 de febrero de 2006, que declaró inconstitucional la disposición del artículo 14 inciso 3 de la Ley de Seguridad Aérea, que, cumplidas ciertas condiciones, permitía derribar aviones secuestrados.

Como es natural, hay que tener en cuenta un dato evidente, a saber, que los tribunales constitucionales no juzgan directamente sobre la moralidad de las acciones o normas sino sobre su congruencia con la Ley Fundamental. Esto establece una diferencia de perspectiva respecto de los autores del Siglo de Oro, que se interesaron directamente por los problemas morales involucrados en este tipo de asuntos. En el caso en cuestión, los artículos más relevantes son los que se refieren a la intangibilidad de la dignidad humana y a la protección del derecho a la vida, materias que, aunque estén recogidas en un texto jurídico, evidentemente tienen un fuerte contenido moral $^{31}$. En definitiva, lo que se busca es determinar si la autorización del uso de la fuerza para derribar esos aviones supone una lesión de la dignidad y vida de los pasajeros y tripulaciones; también es necesario establecer si los medios elegidos por la ley son aptos para conseguir el fin que se busca sin lesionar ciertos principios fundamentales recogidos en la Constitución.

Las razones del Tribunal Constitucional son muy variadas. Algunas tienen que ver con los procedimientos y las competencias que resultan afectadas por esta medida. El Tribunal estableció que los procedimientos contemplados por la ley eran inconstitucionales porque lesionaban las competencias de los Länder (párr. 88-110,155), pero además se pronunció sobre los aspectos de fondo, que son los que aquí nos interesan.

30 La elaboración ordenada del argumento implícito en los desarrollos de los autores escolásticos ha sido llevada a cabo en Kramer, Herbert (1935). The Indirect Voluntary or Voluntarium in Causa, Washington D.C.: The Catholic University of America, pp. 30-73. Un argumento compatible con este, pero elaborado en otros términos, puede verse en MiranDA, Alejandro (2012). "Eutanasia, suicidio asistido y principio del doble efecto. Réplica al profesor Rodolfo Figueroa”. Revista Médica de Chile, Vol. 140, pp. 265-269.

31 "La dignidad humana es intangible. Respetarla y protegerla es obligación de todo poder público" (Art. 1.1 de la Ley Fundamental); "Toda persona tiene el derecho a la vida y a la integridad física. La libertad de la persona es inviolable. Estos derechos solo podrán ser restringidos en virtud de una ley" (Art. 2.2). 
Una constatación fundamental consiste en que el secuestro del avión deja a la tripulación y a los pasajeros en una situación que lesiona su autonomía:

"En este supuesto extremo, que está también marcado por la limitación espacial de un avión en vuelo, los pasajeros y la tripulación se encuentran en una situación sin salida en la que ya no pueden configurar por sí mismos sus circunstancias vitales con independencia de terceros" (párr. 123).

Dicha situación no solo se debe a la acción ilícita de los terroristas, sino que también se da en el supuesto en que el Estado decida intervenir y haga uso de la fuerza para derribar la aeronave:

"Esto convierte a las víctimas que van dentro del avión no solo en objeto de los secuestradores, sino también del Estado que en tal situación recurre a la medida de defensa del inciso 3 del artículo 14 del la Ley de Seguridad Aérea, que los trata como simples objetos de su acción de salvamento para la protección de terceros. La situación de indefensión y la imposibilidad de evitar el destino decidido por los secuestradores caracterizan la situación de las víctimas que van dentro del avión también frente a quienes ordenan y ejecutan su derribo. Los pasajeros y la tripulación carecen de medios de defensa tanto frente a los secuestradores como frente a esa actuación del Estado, debido a las circunstancias en las que se encuentran, que no pueden dominar de ninguna manera. Están entregados sin remedio y sin salida a la decisión estatal que tiene como consecuencia que sean intencionadamente eliminados junto con el avión en el que vuelan. Esta regulación no es compatible con la consideración de los afectados como sujetos con dignidad y derechos inviolables" (párr. 124).

El Tribunal continúa su argumentación ahondando en la idea kantiana de autonomía, que resulta en este caso negada por la acción estatal que lleva a tratar a los pasajeros y a la tripulación como cosas:

"Utilizando su muerte como medio para la salvación de otros, el Estado cosifica a esas personas, al mismo tiempo que las despoja de sus derechos. Cuando la actuación estatal decide unilateralmente sobre sus vidas, se priva a los ocupantes del avión, en su condición de víctimas, precisamente necesitadas de protección, del valor que corresponde al ser humano por el hecho de serlo" (párr. 124).

Muy distinto es el caso en que se derriba un avión secuestrado que está ocupado únicamente por terroristas, situación que el Tribunal autoriza expresamente. Aquí no se está tratando a los ocupantes como cosas: 
"Por el contrario, deriva precisamente de la posición subjetiva del autor del ataque la imputación personal a dicho sujeto de las consecuencias de su comportamiento consciente y que se le haga responsable del acto en el que él lleva la iniciativa. La actuación estatal no desconoce en este caso el derecho al respeto que también al autor del atentado se debe como persona" (párr. 141).

En este caso, no se presenta el problema de la inseguridad en la determinación del real peligro, pues si los ocupantes del avión no quieren utilizarlo como arma tienen diversos medios para mostrar su propósito, entre otros hacer caso a las advertencias que desde abajo hace la autoridad respectiva (párr. 142).

Tampoco considera válido el Tribunal el argumento que sostiene que los ocupantes inocentes del avión de todos modos van a morir: en efecto, "la vida humana y la dignidad de la persona gozan de la misma protección constitucional independientemente de la duración de la existencia física del individuo" (párr. 132). Además, en la práctica resulta muy difícil saber si efectivamente esas personas están irremediablemente perdidas:

"A ello se añade, además, la inseguridad fáctica a la que ya se ha hecho referencia, que caracteriza el supuesto de hecho del precepto impugnado y que necesariamente influye sobre el pronóstico relativo a cuánto durará la vida de las personas que se encuentran en ese avión que se ha convertido en arma de ataque, o a si todavía existe alguna esperanza de salvación. Normalmente será imposible realizar un juicio fidedigno que se pronuncie sobre la circunstancia de que la vida de esas personas ya está perdida de todas maneras" (párr. 133).

Como se ve, la sentencia se aleja de cualquier asomo de lógica consecuencialista y admite que hay bienes que valen por sí mismos, independientemente de su fuerza para hacerse respetar ${ }^{32}$.

\section{5) ANÁLISIS CRÍTICO DE LA DECISIÓN DEL TRIBUNAL CONSTITUCIONAL ALEMÁN}

Ya hemos visto que, desde una perspectiva clásica, el caso que nos ocupa puede ser abordado de modo diferente. Este tiene que ver con la distinción desarrollada por Tomás de Aquino y luego por los autores del Siglo de Oro entre lo que constituye el objeto directo de la voluntad y lo

32 También rechaza la invocación de un supuesto deber de sacrificarse por el bien común, e indica las razones por la que no es aplicable al caso (párr. 135-136). 
que se acepta o tolera de manera puramente indirecta. Ella conduce a la conclusión de que, en principio, la acción de derribar la aeronave es lícita, siempre que se cumplan con las diversas condiciones exigidas para que sea lícito aplicar el principio del doble efecto.

Cabe también preguntarse si, desde la perspectiva kantiana, debe necesariamente aceptarse la conclusión del Tribunal. El Tribunal piensa que la actividad del Estado dirigida a derribar el avión -que lleva a una muerte segura de todos los pasajeros, incluida la tripulación y los demás ocupantes inocentes de la aeronave- significa no considerar a los rehenes como personas, sino cosificarlos, ya que su vida se utiliza como medio para salvar otras vidas. Sin embargo, no parece que esto sea así. De partida, la utilización de una persona como simple medio supone algo que es evidente, a saber, que se es medio en relación con un fin. La segura muerte de los pasajeros inocentes no es un medio para nada, pues no existe relación de causalidad alguna entre su muerte y la salvación de quienes están en tierra y constituían el objetivo del ataque de ese avión transformado en arma. La muerte de los pasajeros inocentes no es procurada ni como medio ni como fin de la actividad de defensa. La defensa se consigue con el solo hecho de derribar el avión, y tal finalidad se obtendría aun en el supuesto de que el avión estuviese tripulado solo por terroristas. Para determinar si el daño que padece una persona fue intentado como medio para un fin, puede utilizarse, en efecto, una sencilla pregunta contrafáctica: ¿realizaría el agente la acción si la víctima del daño no hubiera estado presente? Si la respuesta es afirmativa se concluye que tal daño cae fuera del plan de acción del agente y, por tanto, no es intencional. Parece claro, entonces, que no se está tratando a los inocentes como mero medio. Tampoco se los trata como puro medio por el hecho de lesionar su autonomía, ya que esta ha resultado vulnerada previamente por los terroristas, en una situación que no es imputable al Estado. Tampoco se debe a este la imposibilidad de comunicación con los pasajeros y tripulación, para poder llevar a cabo un diálogo racional sobre el tema. Sin embargo, se podría objetar, por una parte, que no se está cumpliendo el segundo elemento del imperativo kantiano, a saber, la consideración de esas personas, no solo como simple medio sino al mismo tiempo como un fin. De otra parte, se podría pensar que aunque no se los esté reduciendo a la categoría de medio sí se los está cosificando, en cuanto no se les presta la atención que merecen como personas.

Probablemente las dos objeciones sean caras diferentes de la misma moneda. La respuesta supone preguntarnos por el alcance de nuestra responsabilidad moral de tratar siempre de modo explícito a todo el mundo como persona. Como todas las obligaciones positivas, esta obligación es imposible de cumplir de modo absoluto en todo instante de nuestra vida y respecto de todas las personas del mundo. No en vano Kant no pone esta 
parte del imperativo de modo aislado, sino en conjunción con la prohibición de reducir a las personas al carácter de puros medios. Los escolásticos explicaban que los preceptos positivos obligan semper pero no semper et pro semper. Dicho con otras palabras, la finitud humana nos impide considerar explícitamente a todo el resto de los hombres en cada una de nuestras acciones. Respecto de ellos, el tratarlos al mismo tiempo como un fin exige tan solo no reducirlos a la categoría de puro medio para conseguir objetivos ulteriores. Es decir, es lícito simplemente no considerar de modo directo a alguien cuando actuamos, siempre que esa no consideración no incluya su instrumentalización. Es lo que sucede en el famoso dilema del trolley, propuesto por Filippa Foot ${ }^{33}$. En este caso, si hay un motivo razonable, el conductor del vehículo sin frenos puede lícitamente dirigirlo hacia un lado o el otro, aunque de hecho cada una de las posibilidades traerá consigo el atropellar a un número determinado de personas. Cuando el conductor elige salvar a unos dirigiéndose hacia el lugar en que están otros no lo hace porque estime que la vida de estos últimos tenga menor valor. Simplemente lo que está haciendo es otra cosa, a saber, evitando atropellar a un número determinado de individuos ${ }^{34}$. Los peatones que se salvan no viven porque los otros mueren, sino a pesar de su muerte. Es decir, la muerte aquí no es procurada, sino simplemente tolerada. Otro tanto sucede con los pasajeros del avión. La atención a su condición de personas se cumple con el hecho de que se pongan los medios para evitar llegar a una solución extrema, lo que está previsto por la ley alemana, que exigía que esa medida fuera efectivamente una ultima ratio.

Naturalmente cabe afirmar, y con esto pasamos a la segunda objeción, que el solo hecho de considerar a los pasajeros en una medida menor que a los que están en tierra ya implica una cosificación. Sin embargo, esto sucedería también en caso de que no se derribe el avión, aunque esta vez respecto a las personas que están en tierra, atendida la obligación de defensa que tiene el Estado respecto de los ciudadanos ${ }^{35}$. También aquí se podría alegar que el Estado está actuando como si los ciudadanos que están en tierra no existieran. Y si se dice que con cualquier curso de acción que se siga se está actuando mal -0 sea, que un problema moral carece de una

33 Fоот, Philippa (1967). "The Problem of Abortion and the Doctrine of the Double Effect". Oxford Review, Vol. 5, pp. 5-15, reimpreso en Woodward, P. A. (2001) (editor): The Doctrine of Double Effect. Philosophers Debate a Controversial Moral Principle. Indiana: University of Notre Dame Press, pp. 143-155, p. 147.

34 Ceteris paribus los números sí son relevantes, en cuanto se requeriría tener alguna razón fundada para preferir la alternativa que causa mayor número de muertes, atendido el cuidado que debe tenerse por el bien común.

35 LAdiges niega que en este caso estemos en presencia de tal obligación, ya que no existe el "deber de lesionar la dignidad humana" (Ladiges (2008) 133). Sin embargo, lo que está en discusión es precisamente el hecho de que la acción defensiva del Estado constituya efectivamente una violación de esa dignidad. 
solución racional-, entonces, como se sabe, cesa el juicio de reproche, pues a lo imposible nadie está obligado. En otras palabras, una forma de tratar el problema es verlo desde la perspectiva inversa. Imaginemos, en efecto, que, atendido el hecho de que hay una mínima posibilidad de que los pasajeros tomen el control del avión, la autoridad decide abstenerse de derribarlo. Pero luego, contra lo pronosticado, el avión se estrella contra un objetivo estratégico y causa la muerte de miles de personas. ¿Podemos decir que el Estado ha tratado a esas víctimas inocentes como cosas, que no ha atendido a su dignidad, a su carácter de fines, porque no les ha dado la protección a la que tenían derecho? Los gobernantes podrían alegar que lo que estaban haciendo no era sacrificar a los que estaban en tierra en pro de un esperado beneficio de los pasajeros, en suma, que en ningún caso pusieron la vida de unos al servicio de la vida de otros. Simplemente sucede que, en ciertas circunstancias, cuando se prevé como probable que el avión finalmente no se estrellará, es razonable no disparar contra él, para no causar la muerte de los pasajeros inocentes, como también resulta razonable hacerlo si hay seguridad de que será empleado como arma para dirigirse contra otros inocentes. Tenemos, entonces, que la solución clásica permite, en principio, ambos cursos de acción, mientras que la que prohíbe de modo absoluto derribar el avión termina prohibiendo, en último término, ambas cosas, si se aplica su lógica de modo absoluto.

Por otra parte, el argumento de que el hecho de autorizar el uso de la fuerza significa tratar a los pasajeros como parte de un arma no es concluyente. Este era un argumento que empleaban los defensores de la ley para justificar su aplicación: el pasajero forma parte de un arma y debe aceptar que se le trate como tal (párr. 134); y que el Tribunal hace suyo atribuyéndole un sentido muy diferente:

"Esta manera de ver las cosas pone al descubierto y sin disimulo que ya no se considera a las víctimas del secuestro como personas, sino precisamente como parte de una cosa. El ser humano se cosifica en este argumento de forma incompatible con la concepción antropológica constitucional, que parte de la idea de un sujeto destinado a autodeterminarse libremente y que, por tanto, no puede ser tratado como un puro objeto de la actuación estatal" (párr. 134).

Sin embargo, "parte de un arma" son todos aquellos elementos que la componen en cuanto arma. Los pasajeros van, contra su voluntad, sobre un arma, pero no son parte de ella: ni son condición de su funcionamiento ni aumentan su poder ofensivo.

Por último, el Tribunal atribuye relevancia al hecho de que los pasajeros y la tripulación carezcan de medios de defensa frente a la acción del Estado (párr. 124). Sin embargo, no parece que esta sea una circunstancia 
relevante. En efecto, si la acción es en sí misma ilícita, no deja de serlo porque los pasajeros y la tripulación hayan tenido la posibilidad de defenderse. Así, si alguien mata a otra persona con el fin de heredar sus bienes, la acción no es menos injusta, ni la víctima es menos tratada como medio, por el hecho de que esta última haya tenido la posibilidad física de defenderse. Por otra parte, si la acción del Estado es lícita, a quienes resultan dañados por ella no les asiste el derecho de defensa, puesto que tal derecho procede solo contra acciones injustas, o, mejor dicho, contra acciones que se realizan sin derecho. Por ello, quien resulta dañado como efecto colateral de una acción lícita, no goza del derecho de defensa en el sentido de que le sea lícito "repeler la fuerza con la fuerza", es decir, no puede usar medios que importen agredir a quien realiza la acción. Esto lo vio con toda claridad otro gran autor del Siglo de Oro, Francisco Suárez. En su exposición del caso tradicional de acción de doble efecto que tiene lugar en la guerra, Suárez se plantea la pregunta acerca de si es lícito a los inocentes defenderse de aquellos que con justicia atacan su ciudad. La respuesta del Doctor Eximio es que solo pueden hacerlo de un modo puramente defensivo (pura defensione), por ejemplo, impidiendo que la ciudad se queme, pues esto solo implica proteger la propia vida, lo que siempre es lícito; pero no pueden defenderse como atacando (quasi aggrediendo), es decir, no pueden ellos luchar contra el beligerante justo, pues, dice Suárez, los inocentes no padecen, verdaderamente, ninguna injusticia ${ }^{36}$.

\section{6) El PROBLEMA DE LA DETERMINACIÓN DE LAS CIRCUNSTANCIAS FÁCTICAS}

Con todo, el recurso a la doctrina del doble efecto no permite, sin más, validar la ley objeto del debate. En efecto, si, tal como lo señalaron las asociaciones de pilotos y tripulantes, la determinación de que efectivamente el avión secuestrado será empleado como arma resulta casi imposible, entonces faltaría un elemento imprescindible para que pueda aplicarse la doctrina del doble efecto. En este sentido, indica el Tribunal:

"Conforme a las alegaciones formuladas por algunos de los comparecientes en el proceso, por escrito o en la vista oral, no puede aceptarse por este órgano judicial que los requisitos fácticos para ordenar y ejecutar la medida prevista legalmente puedan ser constatados siempre con la exigible seguridad" (párr. 125).

\footnotetext{
36 Sú́rez, Francisco, Commentaria in secundam secundae divi Thomae, scilicet de fide, de spe et de charitate disputationes (póstuma, 1621), tr. 3, disp. 13, sec. 7, n. 19. Se utiliza la edición de Ludovicum Vivés, Parisiis, 1858.
} 
Además, en casos como este, la situación puede cambiar en minutos o segundos (párr. 126-128) y la presión sobre la autoridad es enorme, de manera que existe un serio riesgo de que la decisión se adopte de manera precipitada (párr. 129).

"Es cierto que también en otros ámbitos de regulación de decisiones policiales se dan supuestos en los que no es posible evitar totalmente la inseguridad en los juicios prospectivos. Pero en el caso presente, bajo la vigencia del art. 1.1 de la Ley Fundamental [dignidad de la persona], debe considerarse por completo inadmisible la decisión de matar conscientemente a personas inocentes en una situación desesperada, como son los pasajeros y la tripulación del avión secuestrado, adoptada sobre la base de una autorización legal que permitiera dicha decisión incluso aceptando la inevitable inseguridad de la constatación fáctica” (párr. 130).

Sin embargo, este problema no se relaciona directamente con la cosificación de los pasajeros, sino con un supuesto de hecho que afecta la razonabilidad de la medida o su aptitud para producir el efecto esperado, pues, para que una defensa sea justificada, el ataque debe ser real y no aparente, además de que no deben existir otras medidas alternativas. En este sentido, dicho aspecto de la justificación de la sentencia no sería reprochable en sí mismo. A lo más se podría decir que las nuevas formas de terrorismo son tales que esas dudas acerca de la efectiva intención de los secuestradores parecen muy poco justificadas, pero eso no afecta el fondo del problema, que consiste en que si se logra determinar la realidad del peligro es lícito derribar al avión secuestrado que se empleará como arma ofensiva.

En todo caso, este tipo de problemas muestra la diferencia que existe entre el caso actual y los precedentes tratados en el Siglo de Oro, que en cierto sentido son más unívocos. Para ellos resulta suficiente acreditar el carácter ofensivo de la nave que se tiene enfrente, lo que en esa época no era difícil, mientras que en el caso actual nos enfrentamos con un avión que no va haciendo uso de sus armas, pues no las tiene, sino que solo actuará como arma una vez que sea lanzado contra el objetivo elegido y explote. Cambian, entonces, las circunstancias fácticas de la situación, lo que hace más difícil su juicio, pero no las herramientas conceptuales que permiten aclararla. Sin embargo, a pesar de las diferencias, los autores del Siglo de Oro nos muestran una actitud que no busca ponerse en el plano de las luchas entre maquiavelismo y principismo, sino que afirma la posibilidad de unir convicción y responsabilidad en la actividad del político. En este sentido, sus argumentos no solo aparecen como filosóficamente más fundados que algunos de los que emplea el Tribunal Constitucional alemán, sino políticamente mucho más realistas. 


\section{BIBLIOGRAFÍA}

- Anscombe, Gertrude Elizabeth Margaret (1958). "Modern Moral Philosophy”. Philosophy, Vol. 33, pp. 1-19.

- Bennett, Jonathan (2001). "Foreseen Side Effects versus Intended Consequences". En Woodward, P.A., (editor): The Doctrine of Double Effect. Philosophers Debate a Controversial Moral Principle. Indiana: University of Notre Dame Press.

- Boyle, Joseph (2004). "Medical Ethics and Double Effect: The Case of Terminal Sedation". Theoretical Medicine and Bioethics, Vol. 25.

- Collegit salmanticensis fF. Discalceatorum b. Mariae de Monte Carmeli primitivae observantiae, Cursus theologicus, tr. 13, De vitiis et peccatis (1658) Hemos consultado la edición de Joannis Antonii Huguetan et soc., Lugduni, 1679.

- Finnis, John (1980). Natural Law and Natural Rights. Oxford: Clarendon Press.

- Foot, Philippa (1967). "The Problem of Abortion and the Doctrine of the Double Effect". Oxford Review, Vol. 5, pp. 5-15, reimpreso en Woodward, P.A. (2001) (editor): The Doctrine of Double Effect. Philosophers Debate a Controversial Moral Principle. Indiana: University of Notre Dame Press.

- George, Robert P. (1993). Making Men Moral. Civil Liberties and Public Morality, Oxford: Clarendon Press.

- Kaczor, Christopher (2006). "The Violinist and Double-Effect Reasoning”. The National Catholic Bioethics Quarterly, Vol. 6.

- Kramer, Herbert (1935). The Indirect Voluntary or Voluntarium in Causa, Washington D.C.: The Catholic University of America.

- Ladiges, Manuel (2007). Die Bekämpfung nicht-staatlicher Angreifer im Luftraum unter besonderer Berücksichtigung des \14 Abs. LuftSiG und der strafrechtlichen Beurteilung der Tötung von Unbeteiligten, Seiten: Duncker \& Humblot Verlag.

- Ladiges, Manuel (2008). "Die notstandbedingte Tötung von Unbeteiligten im Fall des $\$ 14$ Abs. 3 LuftSiG -ein Plädoyer für die Rechtfertigungslösung“. Zeitschrift für Internationale Strafrechtsdogmatik, Vol. 3.

- Ledesma, Pedro de (1605), Segunda parte de la Summa, tr. 3, c. 13. Se cita según la edición de Antonia Ramírez, Salamanca, 1605.

- Miranda, Alejandro (2012). "Eutanasia, suicidio asistido y principio del doble efecto. Réplica al profesor Rodolfo Figueroa". Revista Médica de Chile, Vol. 140.

- Nagel, Thomas (1972). "War and Massacre". Philosophy and Public Affairs, Vol. 1. 
- Quinn, Warren (1989). "Actions, Intentions, and Consequences: The Doctrine of Double Effect". Philosophy and Public Affairs, Vol. 18.

- Rodríguez de Santiago, José M. (2006). "Una cuestión de principios. La Sentencia del Tribunal Constitucional Federal alemán de 15 de febrero de 2006, sobre la Ley de Seguridad Aérea, que autorizaba a derribar el avión secuestrado para cometer un atentado terrorista”. Revista Española de Derecho Constitucional, Vol. 77.

- Spaemann, Robert (2003). "Sobre la imposibilidad de una ética teleológica en sentido universal". En SpaEmann, Robert, Limites: Acerca de la dimensión ética del actuar. Traducción de Fernández, Javier y Mardomingo, José, Barcelona: Eunsa.

- Strauss, Leo (1953). Natural Right and History. Chicago: University of Chicago Press.

- Strauss, Leo (1996). Persecución y arte de escribir y otros ensayos de filosofía politica, Valencia: Edicions Alfons el Magnànim.

- SuÁrez, Francisco, Commentaria in secundam secundae divi Thomae, scilicet de fide, de spe et de charitate disputationes (póstuma, 1621). Se utiliza la edición de Ludovicum Vivés, Parisiis, 1858.

- Vitoria, Francisco de (1539). De indis posterior, sive De jure belli hispanorum in barbaros. Se cita según la edición crítica bilingüe de Teófilo Urdánoz (1960) en Obras de Francisco de Vitoria. Relecciones teológicas, Madrid: Biblioteca de Autores Cristianos. 